\title{
O DESAFIO DO DESIGN DA INFORMAÇÃO EM REPRESENTAR O PROCESSO DE GESTÃO DE DESIGN
}

\section{THE CHALLENGE OF INFORMATION DESIGN IN REPRESENTING THE DESIGN MANAGEMENT PROCESS}

\author{
Kammiri Corinaldesi $\operatorname{Aros}^{1}$, M.Sc. \\ Carina Scandolara da Silva², M.Sc. \\ Luiz Fernando Gonçalves de Figueiredo ${ }^{3}$, D.Sc. \\ (1) Universidade Federal de Santa Catarina \\ e-mail:kammiri@gmail.com \\ (2) Universidade Federal de Santa Catarina \\ e-mail: cariscan@gmail.com \\ (3) Universidade Federal de Santa Catarina \\ e-mail: lff@cce.ufsc.br
}

design da informação, gestão de design, processo, fluxograma, mapas conceituais.

O design da informação vem sendo aplicado na elaboração de documentos para que estes sejam compreensíveis e apreensíveis com maior rapidez e precisão. Nesta área do design, processos são largamente representados em uma linguagem visual por meio do uso de diagramas, principalmente os diagramas de fluxo. O objetivo deste estudo é representar visualmente o esboço do processo de gestão de design por meio de um fluxograma. Os procedimentos adotados foram o uso de mapas conceituais como ferramentas de síntese da informação sobre a gestão de design, conceituada por autores da área, para a posterior elaboração do fluxograma. O processo de design é reconhecido e estudado por muito autores, no entanto, o processo de gestão de design necessita um maior aprofundamento de estudo. Nesse sentido, seu mapeamento colabora para a efetiva aplicação nas organizações, bem como para o entendimento pelas pessoas envolvidas. Este estudo contribui para a aplicação de ferramentas do design da informação como forma de representação do processo de gestão de design.

\section{information design, design management, process, flowchart, concept maps}

Information design has been used in the elaboration of documents so that they can be understandable and apprehensible faster and more accurately. In this design area, processes are widely represented in a visual language through the use of diagrams, mainly flow charts. The objective of this study is to visually represent a draft of the design management process through a flowchart using concept maps as a synthesis of information on design management by renowned authors in the area for further development of a flowchart of this process. The design process is recognized and studied by several authors, however, the process of design management need further deepening study. In this sense, their mapping contributes to the effective implementation in organizations, as well as for the understanding of the people involved. This study contributes to the implementation of tools of design information as a form of representation of the design management process. 


\section{$16^{\circ}$ \\ ERGODESIGN USIHC CINAHPA}

\section{Introdução}

Na sociedade contemporânea, a informação compreendida como 'conhecimento comunicado' desempenha um papel central (Capurro; Hjorland, 2007). O avanço da ciência da informação e o desenvolvimento de tecnologias como o microprocessador e a rede de computadores evidenciam isso, com informações cada vez mais disponíveis em maior quantidade e velocidade.

A informação é "[...]um conceito rico e variado, que abrange muitas disciplinas, assuntos e importantes áreas de conhecimento" (Pettersson, 2012: 11). Neste estudo posicionamos a informação no contexto do design da informação, área que desempenha o papel de elaborar documentos que sejam rapidamente e facilmente compreensíveis, sintetizando a informação por meio de representações visuais como figuras, números, palavras, tabelas, gráficos, mapas, pictogramas, desenhos animados e dados geográficos (Passini, 1999; Mozota, 2011). Neste contexto, a temática de representação visual do processo de gestão de design por meio de ferramentas do design da informação como os fluxogramas (diagramas que indicam fluxo), deriva da necessidade de saber como a gestão de design pode ser representada visualmente. Neste sentido, o objetivo deste estudo é representar visualmente um esboço do processo de gestão de design por meio de um fluxograma, usando mapas conceituais como ferramentas de síntese da informação sobre a gestão de design, de acordo com as linhas de pesquisa de autores da área, para a posterior elaboração de um fluxograma deste processo.

Esta pesquisa se caracteriza por ser de natureza teórica, com abordagem qualitativa e objetivos exploratório e descritivo, porque busca primeiramente explicitar conceitos e construir maior familiarização com o problema, para então descrever um objeto de estudo (Gil, 2002). Para tanto foram adotados os procedimentos técnicos de revisão de literatura e o uso de instrumentos como mapas conceituais para síntese de informações sobre processo de gestão de design e ferramentas do design da informação para organização e representação visual do processo. O resultado final desta pesquisa é a proposição do design de um diagrama de fluxo do processo de gestão de design $16^{\circ}$ Ergodesign - Congresso Internacional de Ergonomia e Usabilidade de Interfaces Humano Tecnológica: Produto, Informações Ambientes Construídos e Transporte

$16^{\circ}$ USIHC - Congresso Internacional de Ergonomia e Usabilidade de Interfaces Humano Computador

CINAHPA | 2017 - Congresso Internacional de Ambientes Hipermídia para Aprendizagem.

elaborado com base em literatura da área.

O processo de design é reconhecido e vem sendo estudado por muitos autores, no entanto, $\mathrm{o}$ mapeamento do processo de gestão de design necessita de maior aprofundamento e estudo, o que pode colaborar para facilitar a sua efetiva aplicação nas organizações e entre as pessoas envolvidas na gestão de design, por meio de uma representação visual rapidamente compreensível.

\section{Design da informação e suas ferramentas de representação visual}

Para Horn (1999: 15), o termo design da informação se refere "a arte e a ciência de preparar a informação de modo a que ela possa ser usada por seres humanos, com eficiência e eficácia". Nesta área, o design se ocupa em decodificar informações e apresentá-las de forma visual, o que para Mineiro (2011) requer antes a compreensão do "todo" com seus detalhes e, assim, gerar a síntese visual com informações relevantes. Aproximando isso da gestão organizacional, Mozota (2011), aponta que é o design da informação aprimora o entendimento de processos de decisão e o fluxo de documentos. Da mesma forma, pode-se mapear as informações que concernem ao processo de gestão de design e sintetizá-las em uma única representação visual.

Pettersson (2012), propõe 16 princípios para a utilização do design da informação, conforme apresentado na figura 1 .

\begin{tabular}{|c|c|c|c|}
\hline Harmonia & $\begin{array}{c}\text { Acesso à } \\
\text { informação }\end{array}$ & $\begin{array}{c}\text { Custo da } \\
\text { informação }\end{array}$ & $\begin{array}{c}\text { Ética da } \\
\text { informação }\end{array}$ \\
\hline $\begin{array}{c}\text { Proporção } \\
\text { estética }\end{array}$ & $\begin{array}{c}\text { Facilitar a } \\
\text { atenção }\end{array}$ & $\begin{array}{c}\text { Facilitar a } \\
\text { percepção }\end{array}$ & $\begin{array}{c}\text { Garantia de } \\
\text { qualidade }\end{array}$ \\
\hline $\begin{array}{c}\text { Definir os } \\
\text { problemas }\end{array}$ & $\begin{array}{c}\text { Facilitar o } \\
\text { processamento }\end{array}$ & $\begin{array}{c}\text { Facilitar a } \\
\text { memorização }\end{array}$ & Dar ênfase \\
\hline $\begin{array}{c}\text { Fornecer } \\
\text { estrutura }\end{array}$ & $\begin{array}{c}\text { Proporcionar } \\
\text { clareza }\end{array}$ & $\begin{array}{c}\text { Trazer } \\
\text { simplicidade }\end{array}$ & $\begin{array}{c}\text { Favorecer a } \\
\text { unidade }\end{array}$ \\
\hline
\end{tabular}

Figura 1: Princípios de design da informação Fonte: Petterson (2012: 47)

O autor divide estes princípios em quarto grupos: 


\section{$16^{\circ}$ \\ ERGODESIGN USIHC CINAHPA}

estéticos (representados na figura 1 em vermelho), administrativos (em azul na figura), cognitivos (em amarelo) e funcionais (na cor verde).

Os princípios estéticos dizem respeito à forma, sendo considerada a harmonia e a proporção estética; os princípios administrativos que devem ser levados em consideração são: acesso à informação, custos da informação, ética da informação e garantir a qualidade. Os princípios cognitivos são referentes a compreensão da informação, sendo eles: facilitar a atenção, facilitar a percepção, facilitar o processamento e facilitar a memória. Finalmente, os princípios funcionais consistem em: definir o problema, prover estrutura, $16^{\circ}$ Ergodesign - Congresso Internacional de Ergonomia e Usabilidade de Interfaces Humano Tecnológica: Produto, Informações Ambientes Construídos e Transporte

$16^{\circ}$ USIHC - Congresso Internacional de Ergonomia e Usabilidade de Interfaces Humano Computador

CINAHPA | 2017 - Congresso Internacional de Ambientes Hipermídia para Aprendizagem.

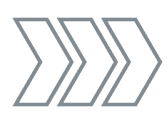

Fluxo

Linear

Circular

Divergente/

Convergente

Multidirecional

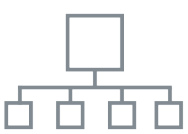

\section{Estrutura \\ Matrizes \\ Árvores \\ Camadas}

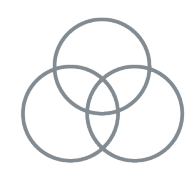

Agrupamento

Sobreposição

Fechamento

Cercado

Vinculados

prover clareza, prover simplicidade e prover unidade.

\subsection{Diagramas como representações visuais}

Na comunicação, mensagens são transmitidas a um receptor através de um meio, e um meio contendo uma mensagem constitui uma representação (Pettersson, 2012). No design da informação essas representações se dão através de uma linguagem visual, constituída por "[...]um conjunto de palavras, imagens e formas 'fortemente acopladas' em uma unidade de comunicação unificada" (Horn, 1999: 27, tradução nossa).

Um tipo de representação visual largamente utilizado no design da informação são os diagramas. Consiste em um recurso gráfico que sintetiza fatos, fenômenos ou relações científicas, sociais, econômicas ou mecânicas, por meio de figuras

geométricas (pontos, linhas, áreas etc.), gráficos ou esquemas (Michaelis, 2014).

Por se tratar de uma representação que concede certa liberdade de elaboração, existem diversos tipos de diagramas com variadas possibilidades de aplicação. Duarte (2010), os classifica em duas categorias distintas: os de conceitos abstratos e os de conceitos realistas. Os abstratos se dividem em quatro tipos: fluxo, estrutura, agrupamento e radial e os realistas em dois tipos: pictórico e gráfico. Dentre cada uma das divisões, existem subdivisões, como pode ser visto na figura 2.

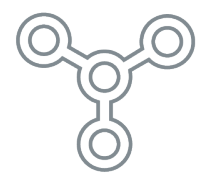

Radial

De um ponto

Com um centro

Sem um centro

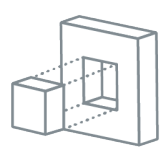

Pictórico

Direção

Localização

Revelação

Processo

Influência

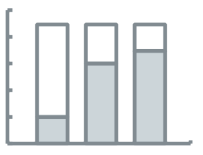

Gráfico

Comparação

Tendência

Distribuição
Figura 2: Classificação dos diagramas Fonte: Adaptado de Duarte (2010: 45)

Duarte (2010), aponta que diagramas de fluxo pertencem à categoria de conceitos abstratos e são dividos em quatro tipos. Na figura 3 é descrita a definição de cada tipo com um exemplo visual.

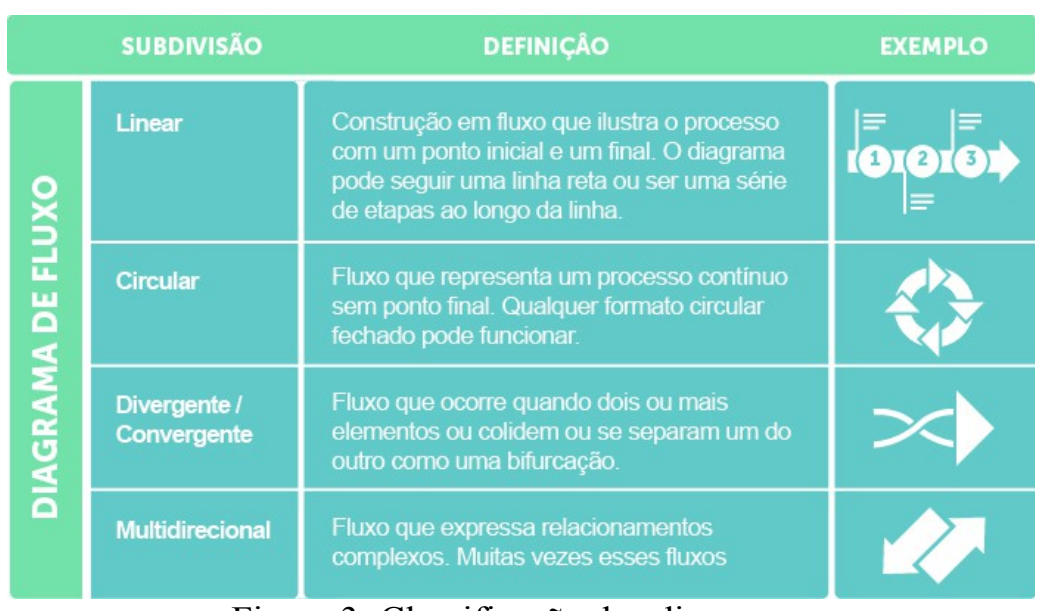

Figura 3: Classificação dos diagramas Fonte: Elaborado pelos autores a partir de Duarte (2010). 


\section{$16^{\circ}$ \\ ERGODESIGN USIHC CINAHPA}

Este estudo foca no tipo de fluxo multidirecional, fazendo uso do fluxograma para a representação esquemática de processo de gestão de design, possibilitando o detalhamento de suas etapas e a demonstração da complexidade de suas relações, se necessário.

\section{Conceituando a gestão de design}

$\mathrm{Na}$ área de design, a gestão de design é um tema que vem sendo abordado por diversos autores, no presente estudo se fez uso das abordagens de Best (2009; 2012) e de Mozota (2011), por possuírem visões complementares entre si na sua concepção sobre a gestão de design. Mozota (2011), defende a gestão de design como uma área em formação, conciliando-a com diversas outras áreas como Marketing, Inovação, Competitividade e Estratégia. Best $(2009 ; 2012)$ a considera como uma área em si, conceituando-a e mostrando sua prática. A partir da teoria das duas autoras, o termo gestão de design pode ser definido de forma sintética como sendo a implementação planejada do design em uma organização para a gestão de pessoas, processos, projetos e atividades que dão suporte para a criação de produtos, serviços, ambientes e experiências.

A gestão do design, portanto, está diretamente interessada pelo lugar ocupado pelo design em uma organização, na identificação de disciplinas específicas de design que são relevantes para resolução de importantes questões de gestão e no treinamento de gerentes seniores no uso eficiente do design. (Mozota, 2011: 94)

As atividades da gestão são divididas em três níveis de tomada de decisão. Best (2009), apresenta estes três níveis como sendo:

Nível estratégico, a habilidade de design para unificar e transformar a visão da organização, define diretrizes, missões e planejamento;

Nível tático ou funcional, a criação de uma função de design na organização, representada pelas equipes, processos e funções específicas necessárias;

Nível operacional de projeto, consiste no primeiro passo para o design integrado, se manifesta nos $16^{\circ}$ Ergodesign - Congresso Internacional de Ergonomia e Usabilidade de Interfaces Humano Tecnológica: Produto, Informações Ambientes Construídos e Transporte

$16^{\circ}$ USIHC - Congresso Internacional de Ergonomia e Usabilidade de Interfaces Humano Computador

CINAHPA | 2017 - Congresso Internacional de Ambientes Hipermídia para Aprendizagem.

produtos e serviços que são gerados.

Best (2009), visualiza a atuação da gestão de design como atividades pertencentes à cada nível, considerando a gestão de design como uma área já estabelecida e sintetizando as definições, o que colabora para a visão da gestão de design como um processo.

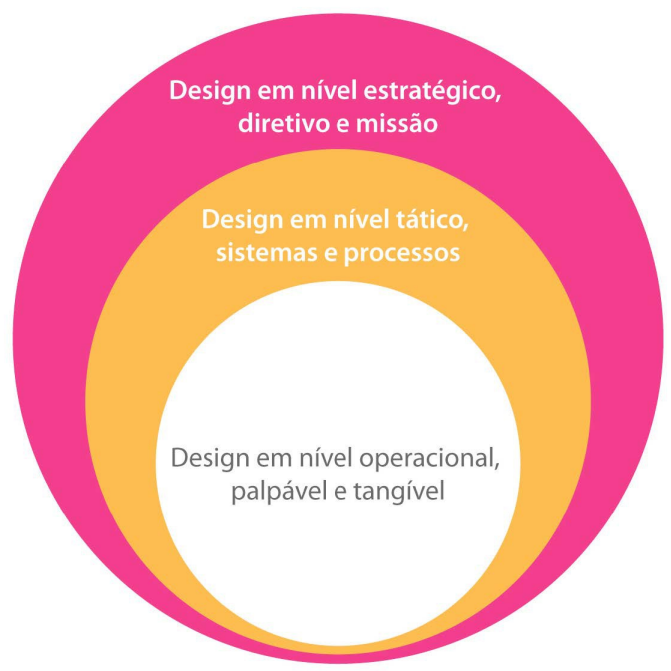

Figura 4: Os três níveis da gestão de design Fonte: Adaptado de Best (2009)

\subsection{Processo de Gestão de design}

Conforme visto, a gestão de design é um processo que envolve atores em níveis diferentes de operação. Best (2009), aponta que os gestores de design devem frequentemente transcender os papéis e se adaptar às situações. Mesmo os diretores de projeto devem definir em que nível integrar o design dentro de uma empresa, levar a empresa a se identificar com os projetos e, enfim, convencer os principais decisores e acionários a financiá-los. O gestor de design deve se assegurar que os métodos, procedimentos e funções internas do projeto agreguem valor à empresa. Para fazer isso, ele deverá, dependendo do caso, formar uma equipe ou coordenar os projetos e orçamentos de diferentes serviços. O designer tem a capacidade de mostrar o potencial de um projeto ou de um estudo e de encontrar soluções para ele, de estabelecer um briefing dentro de um período de tempo e um orçamento definido, e assim, satisfazer as necessidades de seus clientes e consumidores. Best (2009), propõe um fluxo com macro etapas para mostrar o processo de atuação da gestão de 


\section{$16^{\circ}$ \\ ERGODESIGN USIHC CINAHPA}

$16^{\circ}$ Ergodesign - Congresso Internacional de Ergonomia e Usabilidade de Interfaces Humano Tecnológica: Produto, Informações Ambientes Construídos e Transporte

$16^{\circ}$ USIHC - Congresso Internacional de Ergonomia e Usabilidade de Interfaces Humano Computador

CINAHPA | 2017 - Congresso Internacional de Ambientes Hipermídia para Aprendizagem. design, conforme a figura 5.

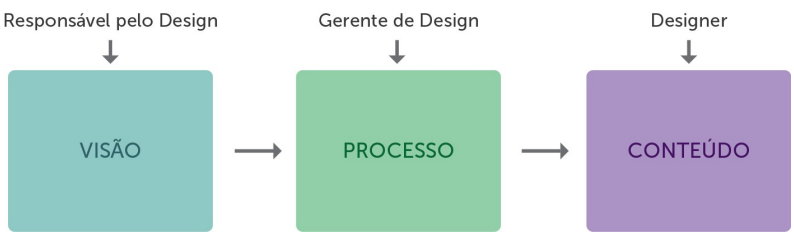

Figura 5: Fluxo da gestão de design Fonte: Adaptado de Best (2009)

Neste fluxo, figuram o responsável pelo design, o gestor de design e o designer como principais atores nos níveis relativos à visão (estratégico), processo (tático) e de conteúdo (operacional), respectivamente. Existem muitas atividades

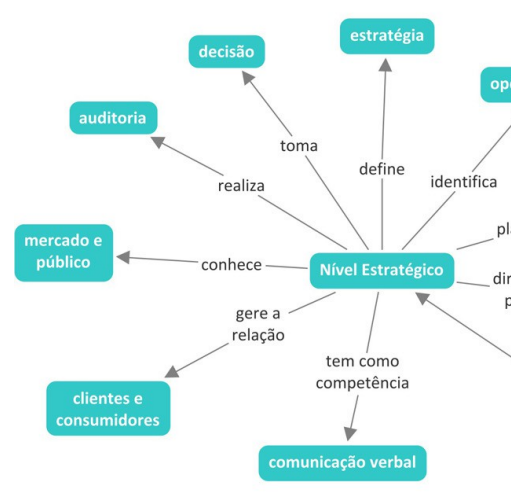

Masini (2001), são diagramas que indicam relações entre conceitos, ou palavras utilizadas na representação destes conceitos. Mapas conceituais são diagramas de relações significativas, que não buscam classificar conceitos, mas sim relacioná-los e hierarquizá-los. Este estudo não se propõe a ensinar como desenvolver um mapa conceitual, mas sim mostrar o resultado a que se chegou usando-os.

Nos mapas conceituais desenvolvidos a partir das teorias de Mozota (2011) e Best (2009) - ver nas figuras 6 e 7 - a gestão de design está ramificada nos três níveis de atuação e, cada nível dividido em suas atividades, características e atores.

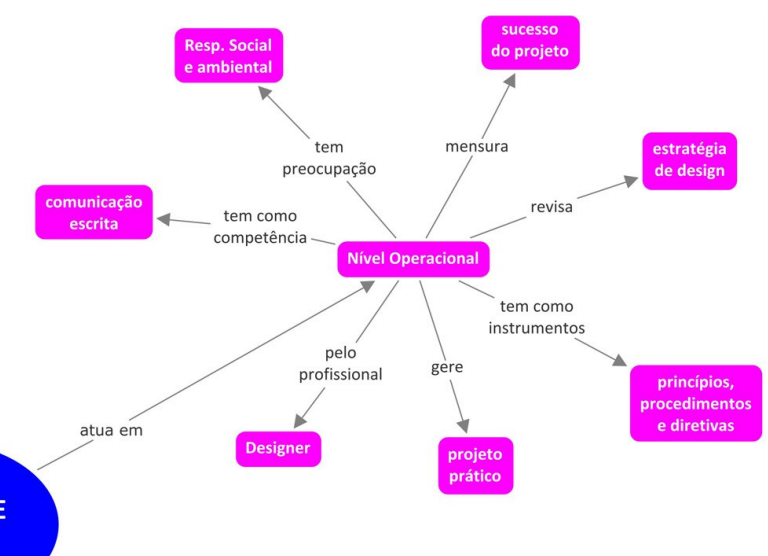

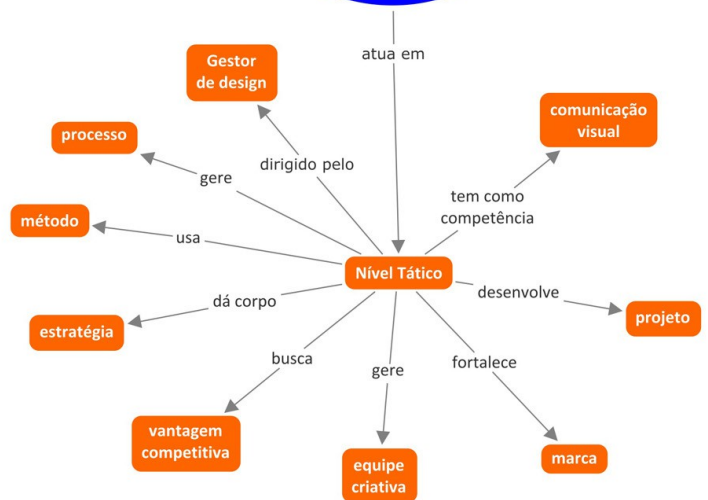

concernentes à cada nível da gestão do design que não estão elencadas no fluxograma da figura 5 , mas que este estudo deseja propor. Com este objetivo, para desenvolver uma síntese do conteúdo sobre o processo de gestão do design e mostrar mais etapas do fluxo do processo de gestão do design, foram desenvolvidos mapas conceituais sobre este assunto a partir das teorias de Mozota (2011) e Best (2009).

Mapas conceituais, de acordo com Moreira \&
Figura 6: Mapa conceitual da gestão do design de Brigitte Borja de Mozota

Fonte: Elaborado a partir de Mozota (2011)

Com a ramificação dos níveis estratégico, tático e operacional nos mapas conceituais das figuras $6 \mathrm{e}$ 7, há uma ampliação de informações em relação ao fluxograma de processo apresentado por Best (2009) na figura 5. Os mapas conceituais trazem mais informações para cada nível da gestão de design, que podem se traduzir em uma 


\section{$16^{\circ}$ \\ ERGODESIGN USIHC CINAHPA}

$16^{\circ}$ Ergodesign - Congresso Internacional de Ergonomia e Usabilidade de Interfaces Humano Tecnológica: Produto, Informações Ambientes Construídos e Transporte

$16^{\circ}$ USIHC - Congresso Internacional de Ergonomia e Usabilidade de Interfaces Humano Computador

CINAHPA | 2017 - Congresso Internacional de Ambientes Hipermídia para Aprendizagem.

especificação mais detalhada sobre o processo de gestão de design, esboçado no fluxograma na próxima seção.
[...] é uma atividade que tem contribuições significativas a fazer para organizações e programas de desenvolvimento de produtos como uma atividade configuradora e produtora de "objetos de fronteira". Se eficientes, estes objetos reduzem assimetrias informacionais entre os diferentes especialistas envolvidos no processo (MINEIRO, 2011, p. 26).

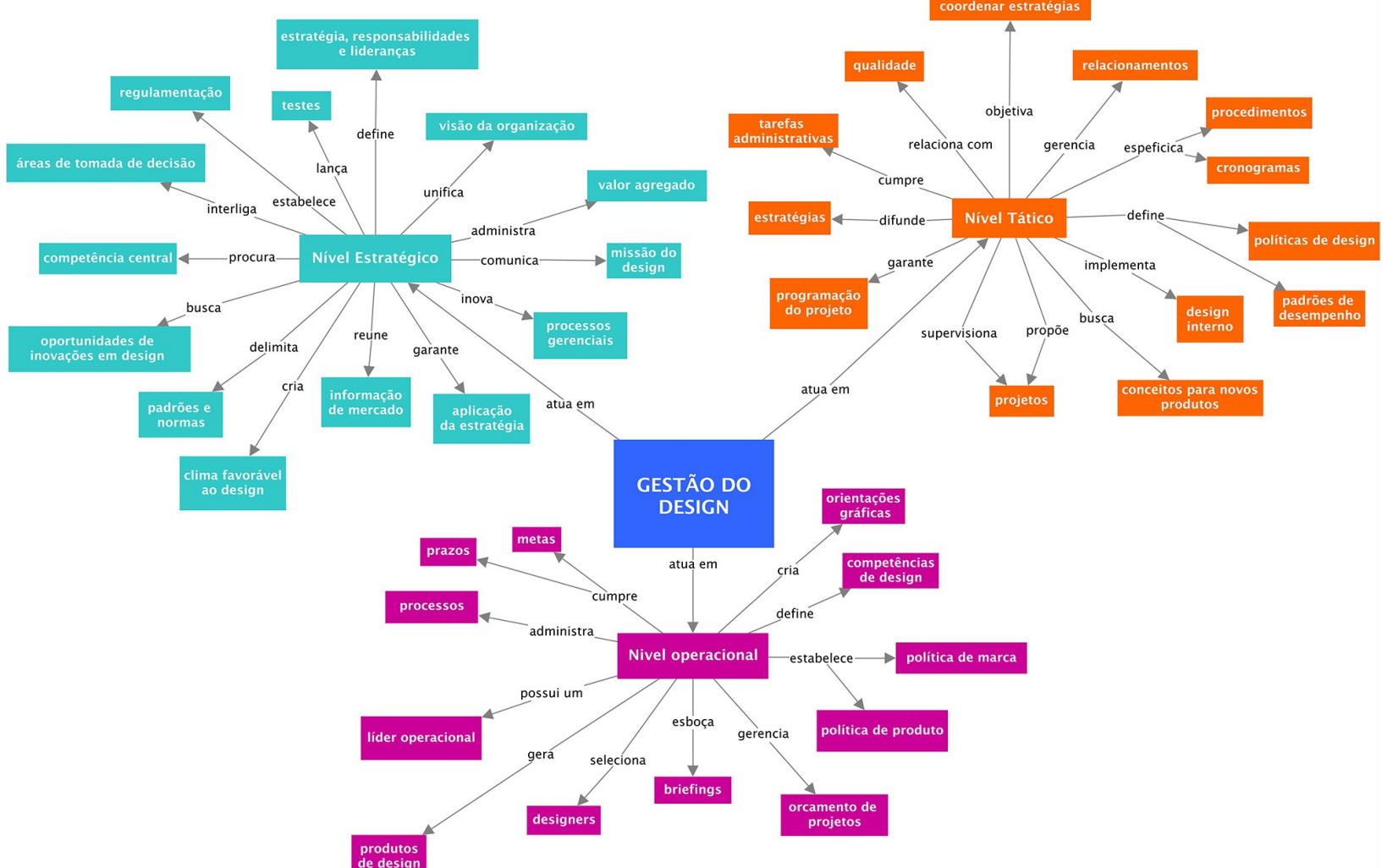

Figura 7: Mapa conceitual da gestão de design de Kathryn Best

Fonte: Elaborado a partir de Best (2009)

\section{Representação visual do processo de gestão design}

"O processo de design é uma combinação de análise (como planejamento estratégico) e síntese" (MOZOTA, 2011: 183). A intenção da representação visual do processo de design por meio de um diagrama de fluxo, conforme visto no item 3, é de elaborar o roteiro de atividades, características e atores do processo de gestão de design ilustrando as atividades concernentes à cada etapa do processo por meio do design de informação.

O design da informação
Este autor também infere que tanto a exploração de informações formalizadas e conhecimentos tácitos ou informais pelos métodos de gestão, quanto as atividades implícitas de design da informação, podem ser vistas como um processo complexo de aprendizagem, que paulatinamente permite aos envolvidos o reconhecimento de um panorama que compreende a identidade da organização, capacidades, tecnologias, e externalidades definidas por mercados, produtos e serviços já existentes. Por isso, a elaboração do diagrama de fluxo do processo de gestão permite que os envolvidos nos diversos níveis da gestão de design possam ter maior integração e compreensão do processo do qual fazem parte.

A fim de organizar as informações obtidas com os mapas conceituais - vistos anteriormente no item 


\section{$16^{\circ}$ \\ ERGODESIGN USIHC CINAHPA}

3.1 - foi desenvolvido um quadro, composto por blocos de informação relativa a cada nível (estratégico, tático e operacional), identificadas por sua similaridade e agrupadas nas categorias de atores envolvidos, atividades a serem executadas e competências pertinentes à cada nível.

\begin{tabular}{|c|c|}
\hline \multicolumn{2}{|c|}{ Nível Estratégico } \\
\hline Atores & Responsável pelo design \\
\hline Atividades & $\begin{array}{l}\text { - Conceber planejamento } \\
\text { estratégico } \\
\text { - Relacionar-se com a alta } \\
\text { administração } \\
\text { - Reunir informação de mercado } \\
\text { - Gerir a relação com os clientes } \\
\text { - Estabelecer regulamentações, } \\
\text { padrões e normas } \\
\text { - Realizar auditorias }\end{array}$ \\
\hline Competências & $\begin{array}{l}\text { - Comunicação verbal } \\
\text { - Unificação da visão } \\
\text { organizacional } \\
\text { - Comunicação da missão do } \\
\text { design } \\
\text { - Tomada de decisões } \\
\text { estratégicas } \\
\text { - Administração de valor } \\
\text { agregado }\end{array}$ \\
\hline \multicolumn{2}{|c|}{ Nível Tático } \\
\hline Atores & Gestor de design \\
\hline Atividades & $\begin{array}{l}\text { - Cumprir tarefas administrativas } \\
\text { - Especificar procedimentos e } \\
\text { cronogramas } \\
\text { - Estabelecer políticas de design } \\
\text { - Definir padrões de } \\
\text { desempenho } \\
\text { - Propor e supervisionar projetos }\end{array}$ \\
\hline Competências & $\begin{array}{l}\text { - Comunicação visual } \\
\text { - Fortalecimento de marca } \\
\text { - Coordenação de estratégias } \\
\text { - Conexão entre os níveis } \\
\text { - Administração de } \\
\text { relacionamentos }\end{array}$ \\
\hline \multicolumn{2}{|c|}{ Nível Operacional } \\
\hline Atores & $\begin{array}{l}\text { Equipe criativa com líder } \\
\text { operacional }\end{array}$ \\
\hline Atividades & $\begin{array}{l}\text { - Desenvolver de projetos } \\
\text { práticos } \\
\text { - Criar orientações gráficas } \\
\text { - Gerenciar orçamentos de } \\
\text { projeto } \\
\text { - Esboçar briefings }\end{array}$ \\
\hline Competências & $\begin{array}{l}\text { - Comunicação escrita } \\
\text { - Mensuração do sucesso de } \\
\text { projetos } \\
\text { - Estabelecer política de marca e } \\
\text { produto } \\
\text { - Administração de processos }\end{array}$ \\
\hline
\end{tabular}

Quadro 1: Informações do processo de gestão de design.

Fonte: Elaborado pelos autores (2017) $16^{\circ}$ Ergodesign - Congresso Internacional de Ergonomia e Usabilidade de Interfaces Humano Tecnológica: Produto, Informações Ambientes Construídos e Transporte

$16^{\circ}$ USIHC - Congresso Internacional de Ergonomia e Usabilidade de Interfaces Humano Computador

CINAHPA | 2017 - Congresso Internacional de Ambientes Hipermídia para Aprendizagem.

O quadro 1, com o levantamento das informações específicas para cada nível do processo de gestão de design, detalhadas e categorizadas; organiza o conteúdo informacional relativo ao processo de gestão de design, e desta forma, dá base para $o$ esboço de um fluxograma.

O fluxograma apresentado na figura 8 é uma evolução do modelo proposto por Best (2009) na figura 5 em conjunto com os mapas conceituais das figuras 6 e 7 e da síntese de informação do quadro 1.

A proposta deste diagrama é apresentar as relações de dependência e direção entre as etapas do processo de gestão de design. O fluxo começa na fase 1, no nível estratégico, tendo como ator o responsável pelo design. A etapa 1 corresponde à verificação de competências, sendo elas: comunicação verbal; unificação da visão organizacional; comunicação da missão do design; tomada de decisões estratégicas e administração de valor agregado. A seguinte etapa corresponde a definição de atividades, as quais são: conceber planejamento estratégico; relacionar-se com a alta administração; reunir informação de mercado; gerir a relação com os clientes; estabelecer regulamentações, padrões e normas e realizar auditorias. A partir das atividades pertinentes ao nível estratégico, o responsável pelo design gera demandas de nível tático, que são encaminhadas ao gestor de design na etapa 3 .

A fase 2 do fluxograma corresponde ao nível tático, onde o ator responsável é o gestor de design e na etapa 1 exige as competências de: comunicação visual; visão para fortalecimento de marca; coordenação de estratégias; conexão entre os níveis e administração de relacionamentos. Quanto à etapa 2, de definição de suas atividades, estas consistem em: cumprir tarefas administrativas; especificar procedimentos e cronogramas; estabelecer políticas de design; definir padrões de desempenho, propor e supervisionar projetos. Ao final da fase 2, o nível tático gera demandas a serem processadas pelo nível operacional. 


\section{$16^{\circ}$ \\ ERGODESIGN USIHC CINAHPA}

$16^{\circ}$ Ergodesign - Congresso Internacional de Ergonomia e Usabilidade de Interfaces Humano Tecnológica: Produto, Informações Ambientes Construídos e Transporte

$16^{\circ}$ USIHC - Congresso Internacional de Ergonomia e Usabilidade de Interfaces Humano Computador

CINAHPA | 2017 - Congresso Internacional de Ambientes Hipermídia para Aprendizagem.
Na fase 3, o nível operacional, que tem como principais atores os designers e o líder operacional, visualize sua atuação e compreenda o alcance de sua interferência na organização.

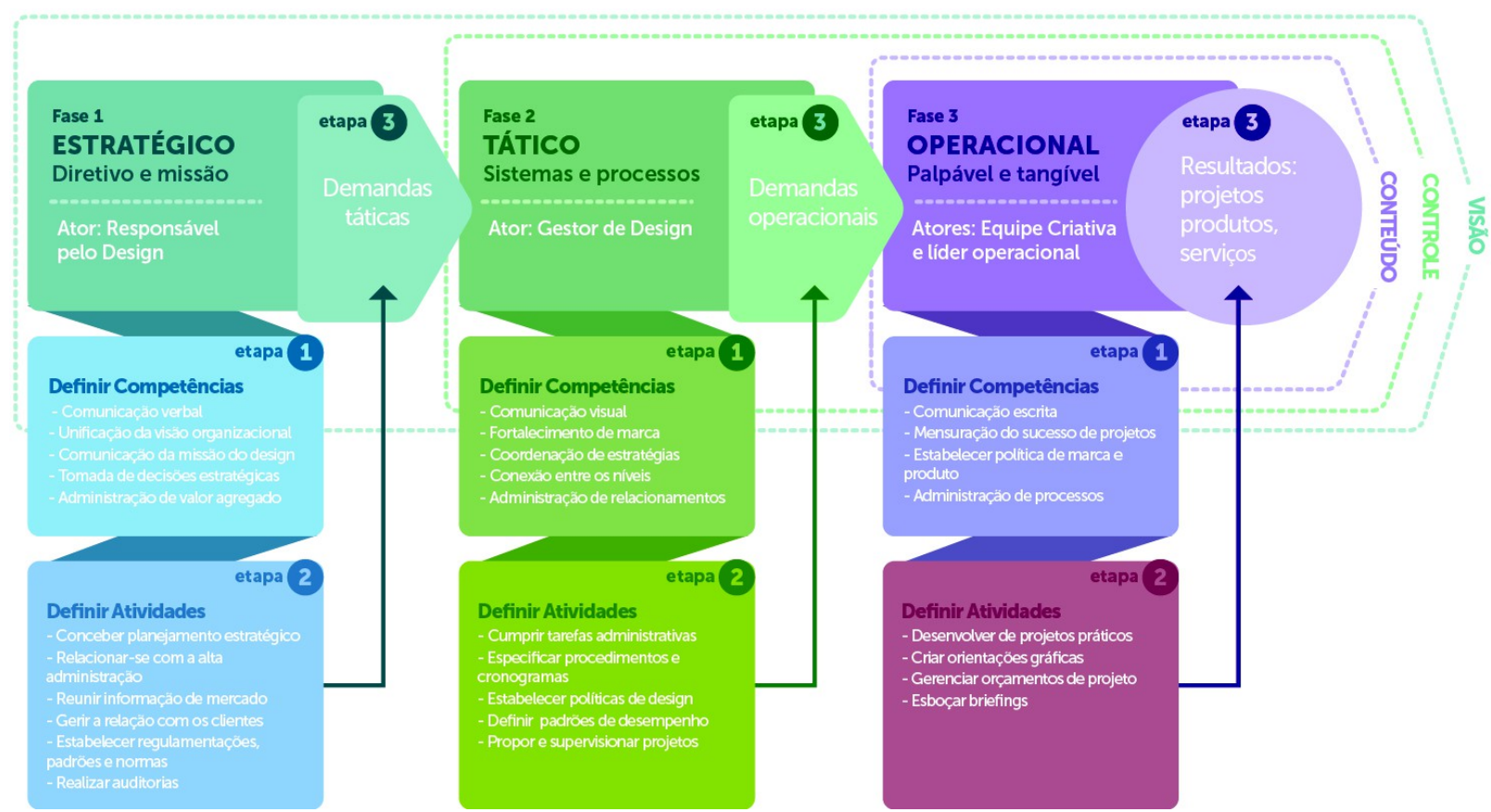

necessitam ter as seguintes competências para atuação no processo de gestão de design: comunicação escrita; mensuração do sucesso de projetos; estabelecer política de marca e produto e a administração de processos. Cabe também a responsabilidade de desenvolver as seguintes atividades: desenvolver projetos práticos; criar orientações gráficas; gerenciar orçamentos de projeto e esboçar briefings. Sendo esta a última fase, tem-se como etapa 3 , a síntese de todo o processo, materializados em projetos, produtos e serviços.

Além disso, durante todo o processo, a visão concebida na fase 1 ampara o controle do processo gerado pela fase 2, do nível tático; enquanto que a fase 3, do nível operacional está alinhada com o controle para a transformação do conteúdo informacional em projetos práticos. Desta forma, o resultado confere com as premissas estratégicas e diretrizes táticas.

O design da informação, através dos diagramas de fluxo, age como estrutura para a compreensão de um processo, pois possibilita a visualização clara do "todo" e seus componentes, auxiliando na identificação e classificação de informações, de maneira que padrões possam ser criados. Da mesma forma, facilita para que cada ator envolvido

Figura 8: Esboço de fluxograma do processo de gestão do design

Fonte: Elaborada pelos autores (2017)

\section{Conclusões}

O presente artigo partiu da problemática de que a gestão de design enquanto processo necessita de maior aprofundamento de estudo e, nesse sentido, realizou uma pesquisa de cunho teórico com abordagem qualitativa, onde, mediante procedimento de revisão de literatura buscou explorar informações sobre o processo de gestão de design e ferramentas do design da informação, para posteriormente cumprir com o objetivo de representar de forma visual o processo de gestão de design por meio de um esboço de fluxograma, usando mapas conceituais como ferramentas de síntese da informação sobre a gestão de design, de acordo com as linhas de pesquisa de autores da área.

Este artigo se configura como um estudo inicial, e propõe um "esboço" de fluxograma justamente pelo estagio primário da pesquisa, no entanto, é pretendido pelos autores prosseguir em um próximo estudo com o aprofundamento na complexidade do diagrama apresentado através da soma de novos levantamentos teóricos e validação 


\section{$16^{\circ}$ \\ ERGODESIGN USIHC CINAHPA}

dos dados em campo, e dessa forma, estabelecer um modelo geral de processo de gestão de design, representado visualmente por meio de ferramentas do design de informação.

$\mathrm{O}$ estudo veio a evidenciar um assunto pouco referenciado na literatura, desta forma contribuindo para a discussão do mesmo.

\section{Referências}

BEST, K. 2012. Fundamentos de gestão do design. Porto Alegre: Bookman.

2009 Le design management: stratégie, méthode et mise en ouvre. Paris: Pyramide.

CAPURRO, R.; HJORLAND, B. 2007. O

Conceito de Informação. Perspectivas em Ciências da Informação, Belo Horizonte, v.12, n.1, p.148-207. Tradução de: Ana Maria Pereira Cardoso; Maria da Glória Achtschin Ferreira; Marco Antônio de Azevedo.

DUARTE, N. 2010. Slide:ology: a arte e a ciência para criar apresentações que impressionam. São Paulo: Universo dos Livros.

\section{GIL, A. C. 2002. Como elaborar projetos de} pesquisa. São Paulo: Atlas.

HORN, R. E. 1999. Information Design:

Emergence of a New Profession. In: JACOBSON, Robert. Information Design. Massachusetts: The MIT Press, Cap. 2. p. 15-34.

MICHAELIS. Dicionário da língua portuguesa. Melhoramentos. Disponível em:

<michaelis.uol.com.br> Acesso em: 15 jun 2014.

MINEIRO, E. F. 2011. Design da informação, modelos mentais e a gestão da inovação:

articulações possíveis. Infodesign, São Paulo, v.8, n.3, p.26-32.

MOREIRA, M. A.; MASINI, E. F. S. 2001. Aprendizagem significativa: a teoria de David Ausubel. São Paulo: Centauro. $16^{\circ}$ Ergodesign - Congresso Internacional de Ergonomia e Usabilidade de Interfaces Humano Tecnológica: Produto, Informações Ambientes Construídos e Transporte

$16^{\circ}$ USIHC - Congresso Internacional de Ergonomia e Usabilidade de Interfaces Humano Computador

CINAHPA | 2017 - Congresso Internacional de Ambientes Hipermídia para Aprendizagem.

MOZOTA, B. B. de. 2011. Gestão do design: Usando o design para construir o valor de marca e inovação corporativa. Porto Alegre: Bookman.

PASSINI, R. 1999. Sign-Posting Information Design. In: JACOBSON, Robert. Information Design. Massachusetts: The MIT Press, Cap. 2. p.15-34.

PETTERSSON, R. 2012. It Depends: ID -

Principles and guidelines. Sweden: Tullinge, 2012. 